\title{
LA ADMINISTRACION MUNICIPAL EN LA EDAD MODERNA: DEL REGIMEN CASTELLANO AL MODELO GADITANO
}

\author{
POR \\ F. JAVIER Guillamón AlVAREZ \\ Universidad de Murcia
}

SUMARIO: Evolución del régimen municipal.-La organización municipal en la edad moderna. - El modelo gaditano

\section{EVOLUCION DEL REGIMEN MUNICIPAL}

Podemos distinguir tres etapas. En una primera, de esplendor, corresponde a los siglos XII, XIII y XIV; otra de transición, entre los siglos $X I V$ y $X V$ y por fin, una tercera de crisis, se extendería a lo largo de los siglos XVI, XVII y XVIII. En este sentido se puede hablar de una cierta uniformidad en todo aquello que se refiere a las obligarquías urbanas, incluida en ellas un determinado grado de permeabilidad social, y de una crónica corrupción en la gestión de los abastos, propios y arbitrios de los pueblos en consonancia también con una escasez de cambios institucionales realmente significativos. A la hora de realizar un estudio puntual, la heterogeneidad prevalece, aún así es viable un acercamiento por la vía del desarrollo normativo. Si acaso el paso de los fueros medievales a las ordenanzas municipales supuso un cambio cualitativo que nos sirve de indicador.

El conocimiento de la población es el primer elemento necesario para conocer el funcionamiento de un concejo. Muchas veces el grado de democratización está en relación directa con el número de habitantes. Otro aspecto fundamental es la pertenencia a realengo, jurisdicción señorial, territorio de órdenes militares, etc.

Posteriormente debiera exponerse la planta del municipio, aportando un organigrama orientativo y dentro de un contexto. Pues conocer el municipio supone conocer también el funcionamiento de instituciones centrales, como el Consejo de Castilla, territoriales -Chancillerías y Audiencias- e instancias inmediatas, esto es, aquellas que poseían las funciones delegadas del poder central, como Superintendentes, Intendentes, Corregidores, Jueces delegados, Alcaldes mayores...

Capítulo aparte merecerán los más genuinos representantes del Concejo: los Regidores que conforman el regimiento, y los Jurados 
que reflejan la más amplia y general caracterización económica y social. Estos cargos podían ser perpetuos, renunciables, arrendables, en régimen de tenencia, elegibles, vinculables, etc... y a ellos correspondía la mayor parte de las cuestiones fundamentales: Procuradurías, Comisiones, Diputaciones... Al margen del resto de los oficios ligados al Ayuntamiento, como Escribanos, Porteros, Alguaciles...

El abastecimiento y el mercado urbano llena de por si un buen porcentaje de la actuación municipal. Cada una de las cinco especies, grano, aceite, carne, carbón y nieve, merecen ya un análisis individualizado. El Concejo redacta y presenta al Consejo de Castilla sus propias ordenanzas municipales, controla a los gremios a través de las mismas, interviene en el régimen laboral, en el reparto de tierras, de agua, arrienda diferentes abastos; tiene los pesos y medidas del fielato, interviene en los précios, regula la actuación de los comerciantes y regatones de ferias y mercados, dirige el pósito, etc...

La hacienda local es el indicador más seguro. Esta va a sufrir reformas e intervenciones por parte del poder central, ya que siempre estuvieron en el punto de mira del ideario político de los ilustrados, sobre todo. Así por ejemplo, el catastro y la única contribución de 1771, la administración de las rentas reales y la acción de la Contaduría General de Propios y Arbitrios, son otros tantos tres hitos fundamentales que hay que tener en cuenta durante el reinado de Carlos III.

Para el conocimiento cabal del municipio moderno es por tanto preciso tener como objeto preferente el patrimonio municipal, distinguiendo el capítulo de ingresos: constituido fundamentalmente por el apartado de propios -fincas rústicas y urbanas, censos, oficios, tierras en general, agua, almudinajes, molinos, juros, hierbas, etc...-, y los arbitrios. Así como los gastos: réditos de censos, salarios, fiestas, limosnas, obras públicas, servicios en general, modas, alumbrado...

Simultáneamente y conjugando criterios sincrónicos y diacrónicos, ha de tenerse en cuenta el proceso de oligarquización municipal, en este caso resulta determinante conocer la procedencia social y los mecanismos utilizados: por lo normal interviniendo en la vida municipal de los territorios de realengo a través de los cargos más prominentes: las Regidurías, vinculación de las mismas en singulaes familias a través de matrimonios o clientelas económicas (testaferros) que constituían un fenómeno social aún poco estudiado: los bandos y el desgaste que inflingen al poder económico del mismo municipio por medio de gestiones usurpadoras: beneficio de tierras, licencias y atracción de campesinos. 
En el trasfondo de todo ello debe encontrarse el reformismo del siglo XVIII y sus ideales de restauración demográfica, económica, cultural, etc... con especial referencia a las reformas administrativas que afectaron a la capacidad política y económica de los municipios, si bien la reducción de las autonomías municipales no era nada nuevo, en último término la debilidad de las haciendas locales quedará puesta de manifiesto. La potenciación de los corregidores, la agrupación de los municipios de las Coronas de Aragón y Castilla en partidos e intendencias y la intervención en las haciendas locales (Ordenanzas de Intendentes, creación de la Contaduría General de Propios y Arbitrios, reformas de 1766, Pragmática de 1783, etc...) no alteraría sustancialmente el régimen municipal ni hizo mella en el dominio oligárquico.

Como ha señalado Fernández ALBALAdEJo en el siglo XVIII se produjo una pugna entre dos modelos de organización monárquica, el administrativo y el judicial. La crisis financiera de 1739 forzó a la Monarquía a optar por la primera, intentando dar vía libre a los procedimientos ejecutivos y liberarse de la atosigante y plúmbea supervisión judicial.

En este sentido, hacia 1779 el conflicto está resuelto, pero más que intervencionismo estatal, lo que hay es una nueva forma de plantear las relaciones entre Monarquía y las ciudades.

La reordenación de las haciendas locales aparecía como una pieza clave dentro del sistema de reforma concebido por ENSENADA abandonándose el criterio exclusivamente fiscalista y depredador.

Los dos mejores ejemplos de intromisión en las competencias tradicionales del Ayuntamiento fueron justamente dos cuerpos institucionalizados: la Administración General de Rentas de la Provincia y la Junta de Arbitrios.

Finalmente, tal y como lo ha apuntado LADERO QUESADA encontramos la culminación de un proceso de cristalización de realidades administrativas ya patentes desde el siglo XV: acentuamiento de la tendencia centralizadora, decadencia de las autonomías urbanas y homogeneización según un modelo castellano.

La ruptura sólo vendría por el conducto revolucionario.

\section{LA ORGANIZACION MUNICIPAL EN LA EDAD MODERNA}

Por debajo del lejano poder central, la vida política cotidiana se desarrolla en el marco de las ciudades y villas que han impuesto su autoridad a las aldeas y pueblos de alrededor y territorio circundante. Desaparecido prácticamente el Concejo abierto, se afirma el Concejo cerrado y la dirección recae en manos de oligarquías nobiliarias que se disputan el control de las ciudades, especial- 
mente las de voto en Cortes. Como ha escrito DOMínguez OrTIZ «había mucho que ganar y mucho que perder en aquellos microcosmos hirvientes de pasión que eran los pueblos de Castilla».

El poder real no permanece impasible ante esta consolidación del poder ciudadano y trata de controlarlo a través sobre todo de la figura del Corregidor y de otras medidas como la adoptada en 1610 mediante un Auto Acordado que dividía todos los municipios castellanos en cinco partidos inspeccionados por otros tantos miembros de la Sala de Gobierno del Consejo de Castilla, cuya finalidad era la de alinear los municipios bajo un patrón manejable y común.

Desde el punto de vista institucional se produce el tránsito del Regimiento al Ayuntamiento, la configuración del mismo supone pasar a un régimen cerrado en el que desaparecen las prácticas electivas, perdiéndose asimismo el sistema de mitad de oficios (oligarquización).

Aparecen nuevos cargos, oficios y funciones municipales que expanden el poder en todos los aspectos de la vida local.

El Cabildo o Ayuntamiento estaba compuesto por un número variable de regidores, elegidos o designados mediante sorteo, aunque de ordinario fueron nombrados por el Rey con carácter vitalicio entre miembros de la nobleza ciudadana. Ya en pleno siglo XVI la práctica totalidad de los municipios importantes estaban dominados por los oligarcas locales.

Históricamente pudo haber sido un contrapeso a esta asamblea nobiliaria la existencia de los Jurados, elegidos por el pueblo para defender sus intereses y controlar la actuación de los regidores, sin embargo en Castilla estos oficios se convirtieron también en vitalicios y hereditarios, "desdibujándose -como dice J. A. ESCUDERO- esa función representativa del gran sector social de las clases medias, y quedando en cierta forma asimilados a los regidores. Teóricamente unos y otros acaparaban el poder ciudadano y concurrían al Consejo Municipal que era presidido por el Corregidor. No obstante en modo alguno puede hablarse de equiparación ya que los Regidores pertenecían a una categoría social superior y su poder era prácticamente decisorio. En Murcia por ejemplo tenían voz pero no voto.

Podemos entonces hablar de un proceso de aristocratización municipal en la Edad Moderna a través de la perpetuación de los regimientos: me permitían detenerme en este punto, que personalmente considero como el más crucial e importante del período que estamos tratando. Me explico, la venta de oficios de Regidores contribuyó en Castilla a que quedaran en manos de los poderosos capaces de adquirirlos, si bien es posible que se produjera un 
interesante fenómeno social, al poder igualmente acceder al gobierno municipal burgueses enriquecidos que bien pudieran romper el hermetismo del control nobiliario, no obstante este hecho no fue tan decisivo, ya que - personalmente también he tenido la oportunidad de estudiarlo para Murcia- los llamémosles «burgueses enriquecidos», adquirían normalmente esos regimientos como forma de ennoblecimiento.

Se impone, pues, hacer una pequeña historia sobre la venalidad de oficios municipales: durante el reinado de Alfonso XI el gobierno de las ciudades y villas experimentó el tránsito del Concejo abierto al del regimiento. El Rey nombra a un número de Regidores que constituyen una asamblea reducida, el regimiento, en cuyo seno se realizan las elecciones, administran, supervisan cuentas, etc... Al principio el nombramiento se hacía por tiempo indeterminado, otorgado por el Rey o por propuesta del Concejo, como era el caso de Murcia, pero pronto prosperó el hacerse vitalicios, y seguidamente o a la par, el nombramiento se vio mediatizado por los intereses privados, y desde el reinado de Juan II, introdujeron la práctica de la llamada renuncia, esto es, propuesta del renunciante según modelo canónico de la resignatio in favorem.

El primer paso estaba dado, pero los oficios todavía no eran propiedad, sólo usufructo vitalicio.

Segundo paso: se trataba de comprar los oficios por juro de heredad -la llamada perpetua y plena propiedad-, Enrique IV enajenó o vendió muchísimos - de ahí el sobrenombre de las - «mercedes»-, los Reyes Católicos al parecer frenaron este proceso, y Carlos V y Felipe II volvieron a las andadas, pero con Felipe II y sobre todo con Felipe IV se acrecentaron, esto es, se creaban nuevos para vender y perpetuar.

Sea como fuere, de las dos maneras, renuncia o venta, los regimientos quedaron enajenados de la Corona $y$ absolutamente privatizados, y al margen del pago de las medias annatas, etc... se convirtieron en cosas de propiedad privada.

El propietario lo transmitía inter vivos o mortis causa, a persona física o jurídica -donde el desglose entre propiedad de oficio y titularidad era más claro-, podían ser vinculados en la mejora del quinto y tercio del mayorazgo, sujetos a censo, etc... lo que significaba la pérdida del control regio sobre el gobierno de las ciudades, sólo quedaba el Corregidor.

La verdad es que la venalidad favoreció la perpetuación y la renovación al mismo tiempo. Los nobles controlaron de manera absoluta el regimiento, alcanzando su cénit en el mismo siglo XVIII a través de la compra del Estatuto de Nobleza para la Ciudad, pero, no olvidemos que los privilegios de hidalguía tambien se compraban. 
En el siglo XVIII no hay acrecentamiento, pero pasan casi todos a ser perpetuos.

El aspirante a Regidor debía acudir a la Cámara de Castilla con la documentación necesaria en la cual se demostraban los requisitos de índole económica y de nobleza, siendo la Cámara la que tras los informes de los Comisarios Regidores de Estatuto, procedería a la expedición del título, debiéndose pagar la media annata.

El control regio de la vida municipal se realizaba como ya hemos dicho a través del Corregidor, gracias a una pragmática de 9 de julio de 1500 se definen virtualmente sus funciones, llegando a ser un personaje independiente del municipio donde actúa, pero dependiente del Rey que le nombra y le controla, esto quedará plasmado especialmente tras el Auto Acordado referido anteriormente, de 1610, por el que los Consejeros del Real de Castilla se convertían en Supervisores de los corregimientos.

Las competencias del Corregidor son amplias: es representante y delegado político del Rey, nombrado para un tiempo limitado -una especie de Gobernador civil en el distrito de la ciudad- y disfrutaba de unas atribuciones judiciales y a la vez militares. Así pues, es Delegado real, interlocutor con el Alto Tribunal, autoridad militar y Gerente del orden público, ostentando poderes de control en los abastecimientos y precios, e interviene también en la administración económica municipal. Es a su vez Delegado de rentas reales $y$ autoridad judicial en lo civil y en lo penal. Convoca y dirige las reuniones del Cabildo y ejecuta luego los acuerdos adoptados. Representaba de alguna manera la normativa de la legislación general del Estado siempre en pugna con la «autonomía municipal», deudora de las Ordenanzas Municipales que regulaban la vida local. De cualquier forma los acuerdos se adoptaban por mayoría y el Corregidor sólo gozaba del voto de calidad, pero la historiografía ha puesto de manifiesto su poder efectivo a la hora de enfrentarse a los Regidores.

Los Corregidores podían ser letrados o militares - de capa $y$ espada-, estos último por su escasa formación jurídica eran asistidos por los Alcaldes mayores, para lo civil y criminal. El cargo estaba retribuido a costa de la hacienda municipal y complementado con los llamados derechos del poyo. Pero jamás fue vendido.

En otro orden de cosas, la oligarquía municipal era beneficiaria de la fiscalidad municipal, gracias a sus numerosas exenciones, desviando parte del producto hacia los sectores privilegiados, o lo que es lo mismo, constituían una vía de distribución del excedente al margen de la esfera de la producción. Resulta esto último consecuencia de la cohabitación del poder central y la oligarquía local, ya que éstas se incardinan en la estructura social y política 
con una extraordinaria capacidad de adaptación a los intereses del Estado como vehículos de la fiscalidad, adquiriendo una forma de poder nada despreciable como lo era el administrativo y fiscal. Las causas fundamentales del endeudamiento municipal se pueden centrar en las malas cosechas, en la suscripción de censos con cargo a los propios, las llamadas sacas para el abastecimiento del Ejército y de la Corte, la compra de baldíos a la Corona, el tanteo y compra de oficios y de jurisdicción, la compra y gestión de alcabalas, tercias y cientos, así como de juros, títulos de la ciudad, pleitos, pago de millones, donativos y repartimientos (normalmente instituyendo censos con cargo a propios hasta su redención), y un largo etcétera que demuestra el extraordinario peso de la presión fiscal, es decir, pagar más con menos al Rey y los acreedores. Los oligarcas acomodaron dicha presión fiscal a sus propios intereses, suscribiendo censos y convirtiéndose en acreedores de su propio municipio, lo que suponía un beneficio económico que se sumaba al político.

Así, pues, la deuda inducía a una mayor presión fiscal, lo que explica la proliferación de impuestos indirectos sobre el consumo en forma de arbitrios; éstos, durante los siglos XVII y XVIII, pasaron de ser casi inexistentes a constituir casi el 80 por 100 de los ingresos municipales. En cuanto al endeudamiento, podemos dar un dato más que significativo: según las Respuestas Generales del Catastro del Marqués de la Ensenada, en 1769 el 22 por 100 de los ingresos totales se aplicaban para pagar réditos de censos. Mucho se podría hablar de las actitudes sociales y políticas de este grupo que, paradójicamente, la Corona necesitaba para mantener el aparato fiscal.

En otro orden de cosas, hablaremos ahora del control económico municipal que se realizaba a través de las ordenanzas municipales, centrándose en las áreas de producción y de circulación de bienes; en cuanto a estos se refiere, se pueden distinguir cuatro aspectos:

1. Intervención sobre pesos y medidas, obligatoriedad de pesar el grano antes de llevarlo a moler a las eceñas, pagándose derechos por las moliendas.

2. Intervención en materia de precios -fijando los precios y tasas-, existiendo instituciones que dependen del Ayuntamiento, como el Repeso y la Alhóndiga, depósito de granos.

3. Control de mercados y ferias por medio de los fieles ejecutores que velaban por el cumplimiento de las condiciones de venta de determinados artículos. Para facilitar ciertos intercambios se eximía a los habitantes del pago de la alcabala por las transacciones realizadas el día del mercado. 
4. Política de abastecimiento o control sobre productos de venta libre y abastos monopolizados.

La distribución de la tarea de gobierno y administración local se realizaba a través del sistema de Comisiones y Diputaciones, que tenían un carácter delegado del pleno del Ayuntamiento para «propios», rentas, obras, abastos, puentes y caminos, etc., dándose cuenta de ellos en los Cabildos ordinarios y extraordinarios que se dirimían por pluralidad de votos.

En cualquier caso se hace imprescindible hacer alguna referencia al siglo XVIII, ya que por los Decretos de Nueva Planta se aplica el régimen castellano a la Corona de Aragón, lo que sin duda uniformó y revistió de tintes aristocráticos al Municipio, especialmente el catalán. Los nombramientos de Regidores hechos por el Rey recayeron en la aristocracia urbana.

La figura del Intendente es la que representa de forma paradigmática la clase de Oficial administrativo borbónico, institución de desigual y sinuosa historia, cuya connotación preferente será la relativa a cuestiones de Hacienda y Guerra, relegando, hasta las reformas de Carlos III, a un segundo plano a los propios Corregidores. A partir de entonces, los Corregidores se consolidaron como correa de transmisión del poder central, por ello se cuidó mucho la selección de sus titulares para que garantizaran la buena marcha de la nueva política administrativa. Se les dio un preciso contenido jurídico durante el reinado de Carlos III, hasta convertirlos en verdaderos funcionarios. De la misma manera, la figura del Alcalde mayor se potenciará y entrará en la segunda mitad del siglo en una fase de expresión jurídica e institucional semejante a la de los Corregidores.

Se conoce también el interés supremo por el régimen municipal. A la creación de la Contaduría General de Propios y Arbitrios, en 1760, siguió, en 1765, la Real Pragmática sobre la libertad de granos, directamente relacionada con la política de abastecimiento de los pueblos españoles. En 1766 se creaban los Diputados y personeros del común; en 1768, los Alcaldes de cuartel y de barrio, en Madrid; en 1769 esta medida se hace extensible a todas las ciudades donde residieran Chancillerías y Audiencias Reales, etc. Medidas que obedecían a justos motivos de índole económica -especulación de alimentos de primera necesidad, monopolios...-, de índole social-mantenimiento del orden público, consecuencias nocivas de la patrimonialización de los oficios municipales (oligarquización)- y de índole propiamente administrativa -como la racionalización municipal, control de sus propios $y$ arbitrios, etc. 


\section{EL MODELO GADITANO}

Responde, tal y como ha subrayado C. CASTRO, a los siguientes criterios: representatividad ciudadana, división de poderes, racionalidad y máxima eficacia de la administración con coste mínimo (pág. 57). Con modificaciones introducidas por el liberalismo doctrinario, a veces casi definitivas, en cuanto deformaban el sentido inicial, será el prototipo político administrativo de la España contemporánea.

Se partió, en un primer momento, de una nueva distribución provincial y municipal, creándose nuevos Municipios con tal de que contaran con más de 1.000 habitantes, con lo cual se apostó definitivamente por la fragmentación, especialmente tras 1835, en que se redujo esta cifra a 100 vecinos, y en 1845, a 30. La intención primigenia era favorecer la participación del ciudadano en el Gobierno, convirtiéndose los Ayuntamientos en vehículos de las nuevas ideas, sirviendo dicha fragmentación como «multiplicador constitucional», y siendo, en último término, las antiguas cabezas municipales, tradicionalmente dominadas por una prepotente oligarquía, las primeras perjudicadas en el control del poder y las rentas. En suma, la implantación de Ayuntamientos constitucionales se llevaría a cabo no sin dificultades objetivas que derivaban de la extraordinaria diversidad nacional, siendo éstas más graves en las zonas rulales de población dispersa, donde la uniformidad era más complicada.

El Decreto de 6 de agosto de 1811, por el que se incorporaban los señoríos a la Corona, aunque de facto no afectó a la propiedad de la tierra, sí supuso el fin del derecho de los señores a nombrar oficios municipales y una unificación en el sistema de provisión: como ha señalado J. GARCíA FERNÁNDEZ, este Decreto supuso un paso decisivo en la reestructuración política del Municipio por establecer la electividad democrática en más de la mitad de los pueblos de España, una insinuante descentralización, y un compromiso político que permitió el mantenimiento de la propiedad agraria en manos de la nobleza terrateniente, a diferencia de Francia, donde la venta de bienes nacionales creó una poderosa burguesía agraria (pág. 243).

Tras las larguísimas discusiones de la comisión constitucional, por los artículos 310,311 y 312 se erigían Ayuntamientos en todos los pueblos con más de 1.000 habitantes, la Ley determinaría el número de componentes, los Alcaldes, Regidores y Procurador o Procuradores Síndicos se elegirían mayoritariamente por los vecinos, todos ellos elegibles a través de elecciones en dos grados, estableciéndose la duración y huecos pertinentes, y lo que es más 
importante, todas las regidurías y oficios municipales perpetuados desaparecerían sin compensación alguna. Pero si cupiera alguna duda sobre la ruptura con la tradicional organización municipal, ésta quedaba saldada con la desaparición de las figuras del Corregidor y Alcalde mayor, sustituidos por un Jefe político directamente nombrado por el poder central. Con todo ello queda cerrado el círculo de lo que los Diputados de Cádiz querían que fuera el Municipio y el papel que debía desempeñar en la nueva concepción del Estado. En este sentido parece clara la determinación de involucrar directamente los Municipios al poder central.

En cuanto al régimen electoral, conviene precisar que las elecciones se celebrarían anualmente en dos tiempos, esto es, a través de un número de compromisarios proporcional al de vecinos, siendo el Jefe político el responsable de su ejecución y, a la vez, catalizador frente a los bandos locales. En definitiva, el debate entre moderados y liberales en torno a la organización municipal se saldó con el encaje del régimen local a la acción del Estado.

La figura del Alcalde es delimitada como resultado de la separación de funciones, quedando como responsable del orden público y Presidente del Ayuntamiento, sometido no sólo a la supervisión de la Diputación Provincial, sino a la tutela efectiva del Jefe político, primera autoridad provincial. En cuanto a las competencias se refiere, se mantuvo el meticuloso control sobre las haciendas locales. Señala GARCíA FERNÁNDEZ que, frente el modelo revolucionario francés de 1789, "el modelo liberal español de 1812-1813 ignora pura y llanamente la existencia de un área de competencias privativas del Municipio e instaura un sistema en el que cualquier competencia es ejercitada por el Ayuntamiento por delegación del poder ejecutivo, a través del Jefe político» (pág. 278). La Instrucción para el gobierno económico-político de las provincias, de 1813, es aplicación de los principios centralizadores y uniformistas de la Constitución. Es por eso que, a fin de cuentas, resulta difícil, pese al carácter revolucionario, hablar de un poder municipal al margen de unas directrices político-administrativas diseñadas por la acción del Estado, con buen número de elementos de origen francés recogidos, más que del período revolucionario, del sistema napoleónico. La democracia liberal de las Cortes de Cádiz cedió a un poder ejecutivo que impidió la verdadera representación ciudadana, tal y como las recientes investigaciones atestiguan, al encontrar que los munícipes seguían siendo los mismos perros con distinto collar. No podemos olvidar la tendencia que existió en las Cortes de Cádiz por convertir los bienes patrimoniales del Municipio en propiedad privada, que estuvo en la base de su programa de desvinculación y desamortiza- 
ción. El endeudamiento secular de los Ayuntamientos pasaría entonces por el fomento de la propiedad individual y la amortización de la deuda pública.

Ahora bien, el camino para la consolidación de los Ayuntamientos constitucionales dependía de la inestabilidad del propio régimen político. Efectivamente, el 25 de junio de 1814 se liquidaba de un plumazo la obra de Cádiz, restableciéndose los Ayuntamientos que habia en 1808. La vuelta al sistema tradicional es inconcusa tras la supresión de las Diputaciones Provinciales, la reintegración de los señoríos jurisdiccionales y la reposición de los regimientos y oficios municipales enajenados.

Como es sabido, la reacción absolutista de Fernando VII anuló por dos veces la obra emprendida por las Cortes de Cádiz y, por ende, la reorganización municipal. Es por eso fundamental tener en cuenta en todo momento el contexto sociopolítico en que se inscribe la problemática municipal para comprender la oposición de las clases privilegiadas al constitucionalismo doceañista. No es de extrañar, como ya llevamos dicho, el inmediato desmantelamiento de la administración municipal en 1814. En 1820, con el retorno del Monarca al sendero constitucional, se vuelve de nuevo al régimen municipal diseñado por las Cortes de Cádiz, con más fuerza aún, si cabe, por el extraordinario peso político de los Ayuntamientos para combatir a la reacción absolutista. Una de las primeras decisiones consistió en renovar los Decretos enajenadores de propios y baldíos. La Ley para el gobierno económico-político de las provincias, de 1823, hace desvanecer los tímidos intentos descentralizadores y consolida el centralismo; como recuerda GARCíA FERNÁNDEZ «la Instrucción de 1823 establece la estructura básica del sistema municipal español hasta nuestros días».

El período que va de la segunda restauración (1823) hasta la revolución de la Granja de 1836 no puede sustraerse a que la realidad político-social española es diferente y no es posible una mera vuelta atrás. Las oligarquías locales debían asumir el carácter movilizador de los Ayuntamientos, de ahí ese sentido híbrido que caracteriza el último tramo del reinado de Fernando VII en lo que al régimen municipal se refiere.

Desde 1836 hasta el inicio de la década moderada se produjo una nueva vuelta a la situación de 1823 , si bien los progresistas tuvieron que ceder en las indemnizaciones a los propietarios de oficios. La Constitución de 1837 articuló el sistema de elecciones a través de un sufragio directo y censitario. Con la caída de Espartero se desvanecen definitivamente las posibilidades de una descentralización relativa. 
Efectivamente, el Ayuntamiento moderado articula el encaje de la oligarquía local en un Estado que, aun asumiendo logros liberales, diseña una organización política de contenido autoritario. El mejor ejemplo de lo que acabamos de decir lo supone, sin duda, el rígido sufragio censitario que permitía votar tan sólo a los mayores contribuyentes. Las elecciones pasaban de los intereses populares para convertirse en una cuestión propia del juego político, o, mejor dicho, de los partidos políticos, a través de los caciques locales. Los progresistas aceptaron el sufragio moderadamente censitario, pero los moderados siempre intentarían elevar la cuota.

No puede hablarse de poder municipal, sino de administración local. De ahí la importancia de la figura del Alcalde; precisamente lo que marcará la diferencia durante el siglo XIX será su origen -si es o no elegido por los ciudadanos-y su mayor o menor independencia. En 1856 y 1868 se producirán nuevas rebajas en el rígido control municipal implantado por los moderados. En fin, el Municipio es el fin de una cadena administrativa; el caciquismo y las consecuencias, aun todavía sin valorarse en sus justos términos de la desamortización de Madoz con sus ventas indiscriminadas por la fe ciega en la propiedad privada, son elementos que deben servirnos de reflexión acerca de lo que pudo haber sido, y desgraciadamente no fue, el sueño gaditano sobre la representatividad ciudadana. 
REALA-1990, núm. 248. GUILLAMON ALVAREZ, F. JAVIER. LA ADMINISTRACION MUNICIPAL ... 
REALA-1990, núm. 248. GUILLAMON ALVAREZ, F. JAVIER. LA ADMINISTRACION MUNICIPAL ...

REALA-1990, núm. 248. GUILLAMON ALVAREZ, F. JAVIER. LA ADMINISTRACION MUNICIPAL ... 